\title{
eSIP-Saúde: Mozambique's novel approach for a sustainable human resources for health information system
}

Keith P. Waters ${ }^{1 *}$, Moises Ernesto Mazivila², Martinho Dgedge ${ }^{2}$, Edgar Necochea ${ }^{3}$, Devan Manharlal ${ }^{4}$, Alexandra Zuber ${ }^{1}$, Beatriz de Faria Leão ${ }^{4}$, Debora Bossemeyer ${ }^{4}$ and Alfredo E. Vergara ${ }^{5}$

\begin{abstract}
Introduction: Over the past decade, governments and international partners have responded to calls for health workforce data with ambitious investments in human resources information systems (HRIS). However, documentation of country experiences in the use of HRIS to improve strategic planning and management has been lacking. The purpose of this case presentation is to document for the first time Mozambique's novel approach to HRIS, sharing key success factors and contributing to the scant global knowledge base on HRIS.

Case presentation: Core components of the system are a Government of Mozambique (GOM) registry covering all workers in the GOM payroll and a "health extension" which adds health-sector-specific data to the GOM registry. Separate databases for pre-service and in-service training are integrated through a business intelligence tool. The first aim of the HRIS was to identify the following: who and where are Mozambique's health workers? As of July 2015, $95 \%$ of countrywide health workforce deployment information was populated in the HRIS, allowing the identification of health professionals' physical working location and their pay point.

HRIS data are also used to quantify chronic issues affecting the Ministry of Health (MOH) health workforce.

Examples include the following:

- HRIS information was used to examine the deployment of nurses trained in antiretroviral therapy (ART) vis-à-vis the health facilities where ART is being provided. Such results help the $\mathrm{MOH}$ align specialized skill sets with service provision.

- Twenty-five percent of the $\mathrm{MOH}$ health workforce had passed the 2-year probation period but had not been updated in the $\mathrm{MOH}$ information systems. For future monitoring of employee status, the $\mathrm{MOH}$ established a system of alerts in semi-monthly reports.

- As of August 2014, 1046 health workers were receiving their full salary but no longer working at the facilities. The $\mathrm{MOH}$ is now analyzing this situation to improve the retirement process and coordination with Social Security.

(Continued on next page)
\end{abstract}

\footnotetext{
* Correspondence: kpwaters@cdc.gov

${ }^{1}$ Division of Global HIV \& TB, Center for Global Health, U.S. Centers for

Disease Control and Prevention, 1600 Clifton Road, MS-E77, Atlanta, GA

30329, United States of America

Full list of author information is available at the end of the article
} 
(Continued from previous page)

Conclusion: The Mozambican system is an important example of an HRIS built on a local platform with local staff. Notable models of strategic data use demonstrate that the system is empowering the $\mathrm{MOH}$ to improve health services delivery, health workforce allocation, and management. Combined with committed country leadership and ownership of the program, this suggests strong chances of sustainability and real impact on public health equity and quality.

Keywords: Human resources information system (HRIS), Health workforce registry, HIV/AIDS, Data use, Deployment, Staffing, Retirement

\section{Background}

In the "decade of action on human resources for health (HRH)" launched by the World Health Organization's 2006 global report [1], significant progress has been made in the development of global health workforce data. Starting with the first sentinel calls by the Joint Learning Initiative [2], a panoply of global calls for workforce data have been made [3-8], and governments and global partners have responded with ambitious investments in national health workforce observatories (led by the World Health Organization (WHO)) and national human resources information systems (HRIS). The US President's Emergency Plan for AIDS Relief (PEPFAR) alone has invested in the development of over 17 national HRIS [9], mostly in Africa, to improve the strategic planning and management of the health workforce involved in human immunodeficiency virus (HIV) service delivery.

Despite this broad investment, a 2012 systematic review of HRIS development globally found that implementation science and other documentation of country experiences in the strategic use of HR data was lacking and that further development in this area is needed [10]. Since then, only a few papers have been published on HRIS in Sub-Saharan Africa: these cover the impact of Kenya's HRIS [11-14], the benefits of Uganda's HRIS [15, 16], and the rollout of an HRIS in Tanzania [17]. A more recent systematic review of HRIS in health care also determined that there is still little published research on the use and impact of HRIS [18].

This case study presents the Mozambique HRIS experience described by the Ministry of Health $(\mathrm{MOH})$ and Jhpiego, the implementing partner developing the HRIS. We make reference to official $\mathrm{MOH}$ publications, supported by data from the component HRIS databases analyzed by Jhpiego. The paper is organized as follows: brief background on the health situation in Mozambique and case presentation covering key aspects of the information value cycle: organizational context and information needs, system development and architecture, implementation and rollout, integration with government payroll and training databases, data quality, and data analysis-providing several strong examples of strategic use of data outputs from the HRIS, followed by a discussion section. The purpose is to document the Mozambican HRIS for the first time, sharing key success factors and lessons learned by Mozambique and contributing to the scant global knowledge base on HRIS.

In recent years, Mozambique has seen encouraging improvements in its health indicators, including reductions in maternal, neonatal, and infant mortality, increases in the coverage of immunization and institutional deliveries, reduction of the malaria mortality rate, expansion of access to tuberculosis (TB) treatment, and a significant increase in the number of persons benefiting from antiretroviral treatment (ART) [19]. Also promising is the increase in health workforce density to population during this period: the ratio of doctors, nurses, and midwives increased from 47.9 to 67.3 per 100000 population from 2005 to 2013 [20]. Key to achieving these improvements has been the sustained action of the $\mathrm{MOH}$, a national environment of economic growth and stability, and, above all, the silent, dedicated, and lasting work of thousands of health workers throughout the country.

The world is aspiring to universal health coverage (UHC) [21], yet it is estimated that 10.3 million additional health workers worldwide are required to close current gaps and ensure UHC delivery [22], and Mozambique ranked 10th from the bottom on the WHO 2010 list of countries with the greatest health workforce deficits [23]. There are just under $40000^{1}$ health workers in Mozambique's public sector (paid from the state budget and "Pro Saude" donor funds), and the sheer deficits across the country are coupled with poor distribution and uneven competency of these health workers, which jeopardize access and quality of health care delivery $[19,24]$. Addressing these constraints is more challenging due to the historical lack of available and updated data on the health workforce that decision makers in the $\mathrm{MOH}$ could use to make more efficient training, allocation, and management decisions. To address this issue, the $\mathrm{MOH}$, with PEPFAR support, initiated the development of a national HRIS to help improve planning and management of health workers countrywide. 


\section{Case presentation}

\section{Organizational context and information need}

The conceptualization and design of the HRIS was based on an assessment of existing systems conducted by the $\mathrm{MOH}$ in 2010 [25]. The $\mathrm{MOH}$ was aware of the advantages information systems bring to the implementation and monitoring of policies and had identified the need for an integrated $\mathrm{HRH}$ information system in its National HRH Development Plan 20082015. The $\mathrm{MOH}$ considered this assessment a required first step. The assessment found that there were several computerized HRIS operating in the $\mathrm{MOH}$. One of the systems was part of the routine $\mathrm{MOH}$ Health Management Information System (HMIS). It was Excel-based and providing periodic information on $\mathrm{HRH}$, by broad categories, available in the health facilities. The other two were part of larger Government of Mozambique (GOM) HR Information Systems: an access-based Personnel Information System (SIP in Portuguese) administrated by the Ministry of State Administration and Public Function (MAEFP), supposed to capture detailed information on personnel, including demographics and staff life-cycle elements (employment status, retirements), and an online Oracle Database of State Employees (eletrônico Cadastro de Agentes e Funcionários do Estado (eCAF)) administrated by the Ministry of Economy and Finance (MEF), related to payroll and linked to other financial and budgetary government systems but with limited information needed for HR management purposes. There were important data inconsistencies among these systems. Moreover, none of them contained up-to-date or complete information, making them ineffective for informing HR decision making.

\section{HRIS development and system architecture}

The $\mathrm{MOH}$ and partners US Centers for Disease Control and Prevention (CDC) and Jhpiego decided that, for sustainability reasons, the new MOH HRIS had to be built upon what already existed, be part of the $\mathrm{MOH}$ HMIS architecture, and be linked to the larger GOM systems. At the time, the MEF was striving for better control of critical government expenditures and interested in ensuring the coverage and data quality of eCAF. Thus, the MEF provided development capacity, internet communication capability, and technical support to the $\mathrm{MOH}$ and made eCAF available, and in return, national-level $\mathrm{MOH}$ HR staff became involved in ongoing data verification and system improvement.

The "concept name" for the Mozambican HRIS became "eSIP-Saúde" (electronic Personnel Information System for health). Figure 1 depicts the existing and envisioned components of the HRIS and its relationships with other $\mathrm{MOH}$ and GOM systems. Core components of eSIP-Saúde are eCAF, serving as a national registry covering all workers paid by the GOM, and the eCAF "health extension," which adds additional healthsector-specific data elements to the registry, including the physical location of workers to the health facility level and professional occupation categories. Both eCAF and the health extension were developed by the MEF's information technology (IT) unit: Center for Development of Financial Information Systems (CEDSIF). The software was developed by CEDSIF's technical staff using open source tools and written in Java. The source code is owned by the MEF. CEDSIF comprises approximately 200 staff (working on multiple projects, not only eCAF), conducts requirementgathering processes, and has system architects, testing, development, and operations departments, plus a wellsupported helpdesk.

\section{Implementation and rollout}

In 2011, building upon the online eCAF employee database began-"extending" it to include additional information on personnel required for HRH management. The idea of this initial phase of the HRIS was to answer the following question: who and where are the health workers in the country?

Starting in 2014, work commenced to extend eCAF to also cover health sector workers not paid by government (e.g., paid by non-governmental organizations (NGOs), donors, or foreign governments).

Through CEDSIF, the MEF provides the informatics infrastructure for the HRIS. Data are entered by $\mathrm{MOH}$ HR staff directly into eCAF via web browsers in provincial and district offices using the MEF's private network. As the CDC-funded development partner, Jhpiego staff serve as technical advisors on HRIS to the $\mathrm{MOH}$. As such, Jhpiego, MOH, CEDSIF, and the MAEFP (in charge of the state Personnel Information System) form a technical team collaborating on system integration, electronic data exchange, indicator development, and specifications. $\mathrm{MOH}$ and Jhpiego do not have direct access to the databases stored on CEDSIF servers; CEDSIF sends a copy to them each month. The fact that CEDSIF, rather than a donor organization, provides the software development and an important part of the IT infrastructure helps to reduce the costs of the HRIS. Using existing government infrastructure has saved an estimated \$367000 in initial costs: on 184 computers (covering each of the 142 districts, 11 provincial health departments ( 2 each), and 20 hospitals), at an average of nearly $\$ 2000$ each including delivery costs, and the construction of a $\$ 20000$ data center at the $\mathrm{MOH}$ central level. Also saved are additional ongoing costs of maintaining servers, internet connection, and network assistance, 


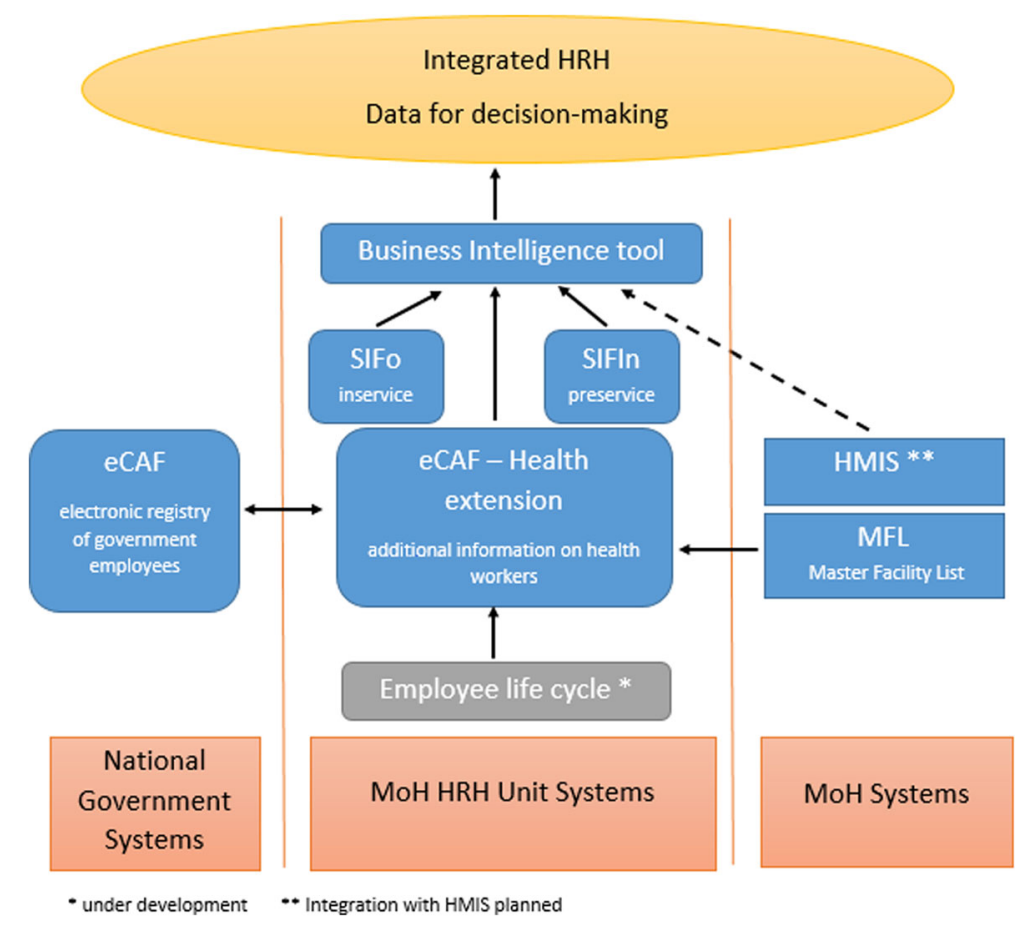

Fig. 1 HRIS (eSIP-Saúde) main components and relationships with other MOH and GOM systems

each just over $\$ 5000$ per month, estimated at $\$ 187000$ per year.

The rollout of the HRIS nationwide involved several partners at different levels. US government (USG) cooperating agencies working with PEPFAR and other USG funds at the provincial level provided additional support for supervision, training, and quality control. At the central MOH level, the Belgian Technical Cooperation (BTC) provided complementary funding for training and supervision. Regular periodic partners' meetings serve to plan, coordinate, and align efforts. This cooperation with various other partners has enabled sharing the cost of trainings and led to many more people being trained.

The current phase of HRIS development, in progress from late 2014, covers the health worker lifecycle (such HR functions as promotions, transfers, retirement) to enable more efficient human resources management.

As of July 2015, $95 \%$ of countrywide health workforce deployment information (36312 out of 38383 health workers) was populated in the eCAF-health extension, and an existing $\mathrm{MOH}$ master facility list was updated to allow the facility-level allocation of workers.

\section{Integration with payroll}

The HRIS allows the identification of the physical location where health professionals are working, as well as their pay point. The HRIS, because it is constructed upon the eCAF database, is integrated with the national payroll system for all government workers (eFOLHA) from which direct bank payments are made.

Approximately $10 \%$ of health workers are paid by non-government sources. Most of these nongovernment workers (known as "fora de quadro") are paid from a pooled donor funds basket ("Pro Saude"). Some are paid by other US partners. The private sector in Mozambique is relatively small and not currently included in the HRIS. Initial focus was on health workers paid by the government. The HRIS was then expanded to capture the health workers not paid by the government and by July 2015 contained around $35 \%$ of them as well. Further, in 2015, the HRIS began to capture community health assistants (agentes polivalentes elementares de saúde (APEs)) - a cadre of community health workers currently supported by donors and not yet in the government payroll.

\section{Training databases}

Independent databases for pre-service training (Sistema de Informação da Formação Inicial (SIFIn) in Portuguese) and in-service training (Sistema de Informação da Formação Continua (SIFo) in Portuguese) are also part of the HRIS. SIFIn contains comprehensive data on current enrolled and graduating health career students from 13 out of $16 \mathrm{MOH}$ pre-service institutions in all provinces in Mozambique. This includes all classes taken and grades attained for students, and profiles of all tutors allowing analysis of 
the future pipeline of health workers, teaching quality, and staffing projections. SIFo captures data on inservice training provided to health workers already working in the public health system. Integrated and aggregated reporting of data from all components of the HRIS is done using a business intelligence tool (Pentaho), allowing comprehensive analysis of current staffing trends and deficits, training allocation, and the future supply and demand for health workers.

\section{Data quality}

An online HRIS community of practice (CoP) was established for assessing data quality. All $\mathrm{MOH}$ human resources managers at the central and provincial levels, as well as some district-level HR managers and cooperation partners, are part of this CoP. Data quality is constantly improved through the HRIS CoP and the use and verification of data (e.g., data inconsistencies, creation of new health facilities, problems with codification of facilities). The CoP periodically disseminates the achievement of indicators among its members and recognizes best performers-rewards, such as laptops, have sometimes been given to provincial HRH units for achieving coverage and quality targets. Additional measures to improve data quality are being designed and planned, such as "proof of life," which is to be implemented by the Ministry of Public Function and CEDSIF, and the verification of data at the district level using a sampling methodology.

Data completeness of the health worker database (the eCAF extension) is assessed against the main eCAF/payroll database monthly. The level of completeness is consistently around $95 \%$, although this fluctuates slightly (completeness for June 2015 was $96.8 \%$ ).

\section{Data use}

Now that the HRIS is populated and the quality of the data closely monitored, more attention is being turned to the information that can be reported from the system and analyses that can inform decision and policy making. The HRIS CoP promotes the use of data at the local level. Provinces such as Cabo Delgado, Tete, Zambézia, Inhambane, Maputo Province, Gaza, and Sofala already use data to produce HRH provincial reports. In 2011, the $\mathrm{MOH}$ created the national Health Workforce Observatory, with technical support from the WHO HRH Unit in Geneva. Members of the observatory include different $\mathrm{MOH}$ units (the HRH directorate, National Institute of Health, and others), National Institute for Statistics, other ministries, national university/school of medicine, and cooperation partners. The Observatory's objective is to establish a national platform for health workforce data analysis to improve policy and planning, and it is starting to use HRIS information: semi-monthly HR reports are being produced and published on the $\mathrm{MOH}$ website
[26], including number of health workers by gender, location (province, district or health facility), cadre, area (urban/rural), health facility type (primary, secondary, tertiary), age, and occupational level, and the ratio of health workers to 100000 population. The HRIS was used as the main source of information for the 2014 Annual National Statistical Overview of Human Resources for Health in Mozambique. It is also being used to examine in more detail aspects related to deployment and management of $\mathrm{HRH}$.

\section{Actual deployment of key providers}

The MOH and Jhpiego used data from the HRIS to examine staffing for human immunodeficiency virus/acquired immune deficiency syndrome (HIV/AIDS) services. Information on in-service training from SIFo (the HRIS inservice training database) was matched with deployment data by cadre at the facility level for Zambézia province, which is the most populous province in the country and has a high number of HIV-infected individuals [27]. The objective of the analysis was to examine the deployment of nurses trained in ART and prevention of mother-tochild transmission (PMTCT) Option B+ (lifelong ART for pregnant women) vis-à-vis the health facilities where ART and/or $\mathrm{B}+$ was being provided. Figure 2 shows a map of where nurses who had received ART/B+ training were deployed (circles) against which health facilities offered ART/B+ (blue crosses). An important finding was that as of March 2015, a significant number of nurses trained in $\mathrm{ART} / \mathrm{B}+$ were deployed to facilities that did not provide any of these services-illustrated by red crosses on the circles-but that were located in districts where rapid scaleup was expected. Around $70 \%$ of nurses trained in ART/ $\mathrm{B}+$ were working in $\mathrm{ART} / \mathrm{B}+$ facilities, whereas the others were deployed to facilities not presently providing these services. The information obtained through this analysis, which was subsequently conducted for other provinces such as Gaza and Inhambane, was presented to the Mozambique CDC/PEPFAR team for discussions on $\mathrm{HRH}$ deployment for HIV service provision.

Data from the HRIS are also being used to inform other workforce initiatives, such as allocation of new health worker graduates. A recent collaborative workforce planning project between $\mathrm{CDC}$ and the Atlanta-based Public Health Informatics Institute (PHII) and Georgia Institute of Technology, Jhpiego, and the $\mathrm{MOH}$ has led to development of a workforce allocation optimization tool that uses data from the HRIS as inputs and runs an algorithm to find the best possible match between numbers of health workers needed by cadre at each provincial location and graduates location preferences for deployment. Allocating these new health workers to both where their skills are needed and where they wish to work is expected to result in higher staff motivation and retention. The $\mathrm{MOH}$ piloted this optimization tool in 2015 to 


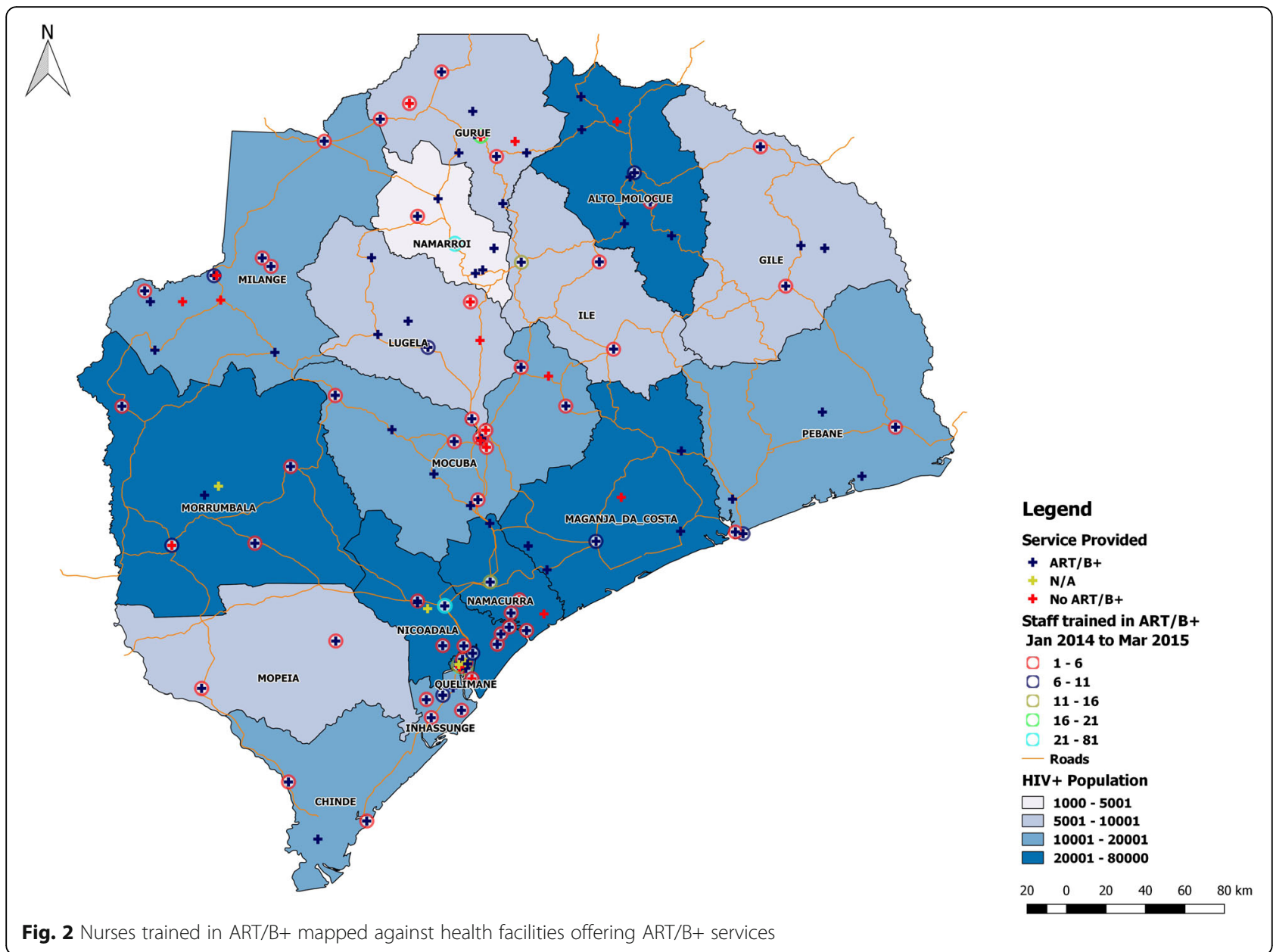

allocate over 1000 health graduates from many different cadres and reported the experience as positively improving the process. The development, use, and impact of the allocation tool are being documented in detail for separate forthcoming manuscripts.

\section{HRIS data for HRH management}

Data offered by the HRIS are starting to highlight and quantify some chronic HRH management issues that affect the health workforce and the $\mathrm{MOH}$ managerial and financial systems. Alerted to this in 2014, the $\mathrm{MOH}$ began performing more in-depth analyses on the information provided by the HRIS in order to better identify the magnitude of the issues and explore solutions. Some of the most relevant findings relate to the following categories: (i) employment status, (ii) staffing efficiencies, and (iii) retirement.

Employment status The process for absorbing health workers onto government payroll, known as nomination, is lengthy. Workers must spend 2 years in probation status until they are eligible to become permanent government employees and attain definitive nomination.
During the probation period, workers receive limited benefits (e.g., cannot be promoted or ask for educational leave). Becoming a permanent employee requires an $\mathrm{MOH}$ manager action approving the employee's paperwork documenting completion of probation.

Analysis of the data in the HRIS revealed that almost 10000 workers $(25 \%$ of the entire $\mathrm{MOH}$ health workforce) had passed the 2-year probation period but not been updated as definitive in the $\mathrm{MOH}$ information systems [28]. To address this issue, in August 2014, the $\mathrm{MOH}$ started a campaign to update the status of the employees and accurately reflect it in the HRIS. For future monitoring of employee status, the $\mathrm{MOH}$ established a system of alerts in semi-monthly reports:

- No alert: more than 3 months until the 2-year limit for probation

- Green: 3 months or less until the 2-year limit

- Yellow: worker has exceeded the 2-year limit for probation by up to 6 months

- Red: worker has exceeded the 2-year limit for probation for more than 6 months 
Another important employment status issue that has emerged involves promotions and salary levels. After 2 years' service as a definitive employee, all workers are due an automatic promotion which includes a salary increase. However, analysis of HRIS data identified more than 10000 health workers that started employment over 2 years ago but were never promoted. HRIS data showed this occurred across all provinces, though two of them (Nampula and Zambézia) accounted for nearly $30 \%$ of the total.

Staffing efficiencies Another area that the HRIS has informed is unpaid leave planning (see Table 1).

As of August 2014, the HRIS found 981 health workers presently on unpaid leave, which represents about $2.5 \%$ of the total Mozambique health workforce [28]. Of these, 354 were on registered leave. At present, the database cannot calculate the duration individuals have been on unpaid leave, but adding the start and end dates to the electronic record will facilitate this analysis in the future and assist the $\mathrm{MOH}$ to determine where action is needed on an individual basis. Provinces with more workers on unlimited leave than the average were Cabo Delgado, Tete, Gaza, Maputo Province, Maputo City, and Central $\mathrm{MOH}$. The latter three (the capital region) accounted for $37 \%$ of the total.

Another staffing issue preliminarily identified by the HRIS is the difference between a health worker's pay point (the location of the budget from which their salary is paid) and the location where the employee actually works. The HRIS has enabled the identification of 165 health workers physically working in one location whose salary was being paid with funds from another location. For instance, the salaries of 31 health workers at Maputo Central Hospital, 39 at Maputo City, and 13 working in the Central $\mathrm{MOH}$ were being paid with funds from other provinces. At the same time, Maputo City and Maputo Province funds were being used to pay the salaries of more than 20 health workers in other locations. Funds from Niassa province, one of the most underserved, were paying for 45 health workers who were working elsewhere.

Retirement If a worker's retirement documents have not been processed when the worker reaches mandatory retirement age, they will cease to work but continue to receive their full salary. They are deemed "desligados" (inactive). It can take from 6 months to over a year to process a worker's retirement, as it requires evidence of their 35 years of service and depends on processing and decision making at the central government level.

As at August 2014, data from the HRIS showed that 1046 health workers were desligados-that is, receiving their full salary but no longer working at the facilities [28]. The estimated cost of this to the $\mathrm{MOH}$ is at least USD 1.5 million per annum. Although the situation occurs in almost all provinces, $41 \%$ of the desligados were in the capital region: Maputo Province, Maputo City, and Central Hospital.

Additionally, there were 628 health workers recorded in the HRIS as actively working beyond the mandatory retirement age-which is 65 years for men and 60 years for women. Again, this situation occurred across all provinces, though two locations (Zambézia and Maputo Central Hospital) accounted for $40 \%$ of these workers.

\section{Discussion}

The case presentation describes experiences of the $\mathrm{MOH}$ and implementing partner in developing the HRIS and using data from it. We presented key findings from analyses of HRH deployment and management data in the HRIS. The finding that around $30 \%$ of nurses trained in $\mathrm{ART} / \mathrm{B}+$ were deployed to facilities not presently providing ART/B+ services might be the result of training occurring ahead of the planned scale-up, but it could also be inefficient provision of in-service training. In the latter case, improvements can be made to align specialized skill sets with service provision, with a particular focus on districts with higher HIV prevalence. Information from the integrated HRIS databases permits this type of analysis on an ongoing basis so decision makers can ensure health workers are deployed more efficiently.

Analysis of employment status data in the HRIS identified more than 10000 health workers that had not received their due promotions. This not only affects the current rank and salary of the health workers, it also affects the amount they are entitled to in their pensions after they retire.

Through monitoring the nearly 1000 employees recorded in the HRIS as on leave, the MOH can take steps to ensure that health workers either return from registered leave in time or that vacancies left by workers on unlimited leave for an unreasonable length of time (over 1 year) can be used to absorb new employees.

Table 1 The three types of unpaid leave for nominated workers in the Mozambican public sector

\begin{tabular}{lll}
\hline Leave type & Conditions of the unpaid leave & No. of workers \\
\hline Unlimited & Indefinite period of time, worker might not have a job to return to & 599 \\
Registered & 6 months to 1 year, worker's same position is held & 354 \\
Special & Indefinite, for special studies (master's or doctoral level) & 28 \\
\hline
\end{tabular}


The mismatches the HRIS identified between pay points and physical working locations can occur because of the relocation of a health worker's spouse (Mozambican law protects the family unit) or due to administrative decisions favoring a specific health worker. Facilities receiving staff paid with funds from other facilities usually accept the new personnel due to the great HRH needs they normally face. Administrative staff at facilities funding the salaries of relocated personnel continue to do so because they fear losing the budgetary allocation for the position.

HRIS data showed over 1000 staff no longer working at the health facilities but still receiving full salary (desligados). Processing retirement depends on another government sector, Social Security, to arrange pension payments. The $\mathrm{MOH}$ is now analyzing this situation to improve the retirement process and coordination with Social Security. It is unclear whether the health workers recorded as still actively working beyond retirement age are continuing to contribute to the health system or are already desligados.

The selected examples demonstrate some of the ways Mozambique is using HRIS data for decision making, to identify and further investigate HRH issues-and if necessary target geographical areas where they will have most impact.

The $\mathrm{MOH}$ and Jhpiego attribute the successful implementation of eSIP-Saúde to the following key factors, all important for the system's sustainability:

i) Investing time in strong engagement with leadership and engendering active support from decisionmaking stakeholders. The extensive intersectoral collaboration between many diverse stakeholders demonstrates their united belief in the viability of the HRIS to produce results useful for decision making.

ii) Conducting a customized assessment of existing systems and procedures prior to system design. The careful approach chosen has helped to foster electronic exchange of information with other government and HRH information systems (e.g., SIFo and SIFIn) and ensure eSIP-Saúde is aligned with Mozambique's national enterprise architecture frameworks. Increasing interoperability and combining data from different systems will enable generation of more powerful analyses and provide the evidence needed to drive decisions on health planning and policy.

iii) Building upon and linking existing $\mathrm{MOH} / \mathrm{GOM}$ owned systems and infrastructure to the maximum extent possible. Developing eSIP-Saúde this way has facilitated broad acceptance by the $\mathrm{MOH}$ and the many stakeholders engaged at other ministries and agencies and yielded savings estimated at \$367 000 in initial infrastructure and $\$ 187000$ per year in maintenance and operational costs. Over the 5 years of the project, this amounts to an estimated \$1 371 000 (US dollars). iv) Utilizing local technical support and building the capacity of the MOH (district, provincial, and national HRH managers) and CEDSIF.

v) Avoiding the proliferation of multiple partial or geographically focused HRH information systems. The HRIS approach in Mozambique has helped to stop partners duplicating efforts and to work together with defined roles.

vi) Continuous process of evolution and development through the dynamic involvement of key stakeholders. Input from the online CoP where users send alerts for required modifications enables constant validation and error correction of the system data. This provides the $\mathrm{MOH}$ with ownership of an evidence base that can be used to demonstrate the impact of not addressing HR issues to decision makers in other ministries. The process of retirement, for example, involves salaries, pensions, and other factors beyond $\mathrm{MOH}$ control and requires coordination with MEF for implementation.

The few other recent papers on HRIS in Africa describe some similar challenges, success factors, and benefits critical for improving the countries' health systems. However, whereas both Kenya and Tanzania developed new systems [11, 17], and Uganda adopted (and adapted) the open source iHRIS software [15], Mozambique is the only documented example of a country integrating and extending existing national government systems for the HRIS. This novel approach is demonstrating rapid progress in a relatively short time and offers what may in the right setting be a faster and more cost effective alternative. This resonates with Driessen et al.'s finding that although the full cost of HRIS implementation can be daunting the benefits of HRIS investments are similar staggering in magnitude and have the advantage of being long-lasting [16]. The figures calculated for Mozambique do not take into account recurrent costs of any ghost workers and/or non-motivated workers, aspects which are to be examined in more detail in the future. As eSIP-Saúde is still being developed, further assessments are recommended, as the system matures, to provide evidence that the HRIS is stable, efficient, transparent, and sustainable in the long term.

We recommend Ministries of Health and other government sectors explore how to develop synergies among their information systems. For example, countries developing automated payroll systems could explore whether it might be used as the basis, or as a support element, for sectorial HR systems such as health. In Mozambique, lessons learned from the successful extension of the national registry of government employees (eCAF) to cover additional data elements and non-government employees for health can be used to 
create similar approaches for other sectors, such as education and agriculture, and build a web-based national government HR management information system.

\section{Conclusions}

The Mozambican system is an important example of an HRIS built on a local platform with local staff. Notable models of strategic data use demonstrate that the system is empowering the $\mathrm{MOH}$ to improve health services delivery, health workforce allocation, and management. Combined with committed country leadership and ownership of the program, this suggests strong chances of sustainability and real impact on public health equity and quality.

\section{Endnotes}

${ }^{1}$ Figures used in the article are consistent as at time of writing. At time of publication, the number of public sector HCWs (paid from the state budget and Pro Saude donor funds) has increased to 52213.

${ }^{2}$ Proof of life is verification, in accordance with Mozambican law, that a government health worker is alive. The law mandates all government employees to periodically present themselves before a government official at designated locations.

\begin{abstract}
Abbreviations
APE: Community health assistant (Agente Polivalentes Elementares de Saúde); ART: Antiretroviral therapy; BTC: Belgian Technical Cooperation; CDC: US Centers for Disease Control and Prevention; CEDSIF: Center for Development of Financial Information Systems (Centro de Desenvolvimento de Sistemas de Informação e Finanças); eCAF: Registry of GOM Employees (eletrônico Cadastro de Agentes e Funcionários do Estado); eSIPSaúde: concept name for Mozambique's electronic integrated HRIS for health; GOM: Government of Mozambique; HCW: Health care worker; HIV/ AIDS: Human immunodeficiency virus/acquired immune deficiency syndrome; HMIS: Health Management Information System; HRH: Human resources for health; HRIS: Human resources information system(s); IT: Information technology; MEF: Ministry of Economy and Finance; MFL: Master Facility List; MOH: Ministry of Health (MISAU); NGO: Nongovernmental organization; PEPFAR: US President's Emergency Plan for AIDS Relief; PMTCT: Prevention of mother-to-child transmission of HIV; SIFIn: PreService Training Information System (Sistema de Informação da Formação Inicial); SIFo: In-Service Training Information System (Sistema de Informação da Formação Continua); SIP: Personnel Information System (Sistema de Informação de Pessoal); TB: Tuberculosis; USG: United States government; WHO: World Health Organization
\end{abstract}

\footnotetext{
Acknowledgements

The authors would like to gratefully acknowledge the support of staff at the many organizations that have contributed to the development and implementation of Mozambique's HRIS - this includes the Ministry of Health, Ministry of Economy and Finance, Ministry of State Administration and Public Function, Jhpiego, CDC Mozambique, and other partners. The findings and statements in this report are those of the authors and do not necessarily represent the official position of the Centers for Disease Control and Prevention (CDC). This paper has been supported by the President's Emergency Plan for AIDS Relief (PEPFAR) through the CDC Cooperative Agreement No. 5U2GPS001542 "Strengthening Safe Hospitals and Clinics in HIV/AIDS Prevention Activities in Mozambique."
}

\section{Authors' contributions}

$A V, D B$, and $E N$ conceived the paper. KW and EN wrote the first draft, with input from $A Z, D M$, and $A V$. All contributed to subsequent drafts, and all authors reviewed and approved the final draft.

\section{Competing interests}

The authors declare that they have no competing interests.

\section{Author details}

'Division of Global HIV \& TB, Center for Global Health, U.S. Centers for Disease Control and Prevention, 1600 Clifton Road, MS-E77, Atlanta, GA 30329, United States of America. ${ }^{2}$ Ministry of Health, Mozambique, Av. Eduardo Mondlane, No. 1008, Maputo, Mozambique. ${ }^{3}$ Jhpiego/Johns Hopkins University, 1615 Thames Street, Baltimore, MD 21231, United States of America. ${ }^{4}$ Jhpiego Mozambique, Rua Jose Mateus 27, Maputo, Mozambique. ${ }^{5}$ CDC Mozambique, JAT Complex 4, 7th Floor, Ave. Zedequias Manganhela 267, Maputo, Mozambique.

Received: 26 February 2016 Accepted: 28 September 2016

Published online: 05 November 2016

\section{References}

1. Working together for health: the world health report 2006. Geneva: World Health Organization; 2006. Available from: http:/www.who.int/whr/2006/ whr06_en.pdf [Last accessed 05 Oct 2016].

2. Joint Learning Initiative. Human resources for health: overcoming the crisis. Cambridge: Harvard University Press; 2004.

3. The Kampala Declaration and Agenda for Global Action. First global forum on human resources for health. Kampala: Global Health Workforce Alliance; 2008. Available from: http://www.who.int/workforcealliance/knowledge/ resources/kampala_declaration/en/index.html [Last accessed 05 Oct 2016]

4. World Health Organization. WHO global code of practice on the international recruitment of health personnel. Resolution adopted at the Sixty-Third World Health Assembly. Geneva; 2010. http://apps.who.int/gb/ ebwha/pdf_files/WHA63/A63_R16-en.pdf [Last accessed 05 Oct 2016].

5. World Health Organization. World Health Assembly Resolution 60.27: strengthening health information systems. Geneva; 2007. Available from: http://apps.who.int/gb/ebwha/pdf_files/WHASSA_WHA60-Rec1/E/reso-60en.pdf [Last accessed 05 Oct 2016].

6. African Union. Conclusions and recommendations from the high level inter-ministerial technical consultation on strengthening political support for health worker development in Africa. 2007. Gaborone, Available from: http://www.hrh-observatory.afro.who.int/images/Document_Centre/ recommend_gaborone_english_03_07.pdf [Last accessed 05 Oct 2016].

7. European Commission. European programme for action to tackle the critical shortage of health workers in developing countries, 2007-13. 2006. Brussels, Available from: http://eur-lex.europa.eu/LexUriServ/LexUriServ. do?uri=COM:2006:0870:FIN:EN:PDF [Last accessed 05 Oct 2016].

8. Pan American Health Organization. Pan American Sanitary Conference Resolution CE140.R13: regional plan of action for human resources for health 2007-2015. Washington, DC; 2007. Available from: http://www1. paho.org/english/gov/ce/ce140.r13-e.pdf [Last accessed 05 Oct 2016].

9. The U.S. President's Emergency Plan for AIDS Relief (PEPFAR). Fact sheet 2015. Available from: http://www.pepfar.gov/press/238801.htm [Last accessed 05 Oct 2016].

10. Riley PL, Zuber A, Vindigni SM, et al. Information systems on human resources for health: a global review. Human Resources for Health; 2012. p. 10. Available from: http://www.human-resources-health.com/content/10/1/7 [Last accessed 05 Oct 2016].

11. Waters KP, Zuber A, Willy RM, et al. Kenya's health workforce information system: a model of impact on strategic human resourcespolicy, planning and management. Int J Med Inform. 2013;82(9). Available from: http://www.jimijournal.com/article/S1386-5056(13)00132-9/abstract [Last accessed 05 Oct 2016].

12. Appiagyei AA, Kiriinya RN, Gross JM, et al. Informing the scale-up of Kenya's nursing workforce: a mixed methods study of factors affecting pre-service training capacity and production. Hum Resour Health. 2014;12:47. Available from: http://human-resources-health.biomedcentral.com/articles/10.1186/ 1478-4491-12-47 [Last accessed 05 Oct 2016].

13. Oluoch $T$, Muturi $D$, Kiriinya $R$, et al. Do interoperable national information systems enhance availability of data to assess the effect of scale-up of HIV 
services on health workforce deployment in resource-limited countries? Stud Health Technol Inform. 2015;216:677-81. Available from: http://ebooks. iospress.nl/publication/40295 [Last accessed 05 Oct 2016].

14. Wakaba M, Mbindyo P, Ochieng J, et al. The public sector nursing workforce in Kenya: a county-level analysis. Hum Resour Health. 2014;12:6. Available from: http://human-resources-health.biomedcentral.com/articles/10.1186/ 1478-4491-12-6 [Last accessed 05 Oct 2016].

15. Spero JC, McQuide PA, Matte R. Tracking and monitoring the health workforce: a new human resources information system (HRIS) in Uganda. Hum Resour Health. 2011;9:6. Available from: http://human-resources-health. biomedcentral.com/articles/10.1186/1478-4491-9-6 [Last accessed 05 Oct 2016].

16. Driessen J, Settle D, Potenziani D, et al. Understanding and valuing the broader health system benefits of Uganda's national human resources for health information system investment. Hum Resour Health. 2015:13:49. Available from: https://human-resources-health.biomedcentral.com/articles/ 10.1186/s12960-015-0036-0 [Last accessed 05 Oct 2016].

17. Ishijima H, Mapunda M, Mndeme M, et al. Challenges and opportunities for effective adoption of $\mathrm{HRH}$ information systems in developing countries: national rollout of HRHIS and TIIS in Tanzania. Hum Resour Health. 2015;13: 48. Available from: http://human-resources-health.biomedcentral.com/ articles/10.1186/s12960-015-0043-1 [Last accessed 05 Oct 2016].

18. Tursunbayeva A, Pagliari C, Bunduchi R, et al. Human resource information systems in health care: protocol for a systematic review. JMIR Res Protoc. 2015;4(4):e135. Available from http://www.researchprotocols.org/2015/4/ e135/ [Last accessed 05 Oct 2016].

19. Ministry of Health. Health sector strategic plan (Plano Estratégico do Sector da Saúde [PESS]) 2014-2019.

20. Relatorio de balance de 9 anos da Direccao (2005-2013). Republic of Mozambique, Ministry of Health, Human Resources Directorate. Maputo: Ministry of Health; 2014. p. 44. Maps 4 and 5.

21. Campbell J. Towards universal health coverage: a health workforce fit for purpose and practice. Bull World Health Organ. 2013. Available from: http://www.who.int/bulletin/volumes/91/11/13-126698/en/ [Last accessed 05 Oct 2016].

22. Addressing the global health crisis: universal health protection policies/ International Labour Office, Social Protection Department. Geneva: ILO; 2014. (Social protection policy papers; Paper 13). Available from: http:// www.lo.org/wcmsp5/groups/public/_ed_protect/—soc_sec/documents/ publication/wcms_325647.pdf [Last accessed 05 Oct 2016].

23. WHO global atlas of the health workforce, November 2010. Available from: http://www.who.int/hrh/resources/57_countries_chart.pdf[Last Accessed 05 Oct 2016].

24. Ministry of Health of Mozambique. National plan for health human resources development 2008-2015.

25. Ministry of Health. National directorate of human resources for health: analysis of the human resources for health information systems in Mozambique. 2010.

26. Republic of Mozambique, Ministry of Health. http://www.misau.gov.mz/ index.php/observatorio-de-rh [Last accessed 05 Oct 2016].

27. National survey on prevalence, behavioral risks and information about HIV and AIDS in Mozambique (2009 INSIDA).

28. Improving the management of $\mathrm{HRH}$ based on evidence generated from eSIP-Saúde (Melhoria de gesta o de RHS com base em evidencias geradas atrave s do eSIP-Saúde). Republic of Mozambique: Ministry of Health, Human Resources Directorate; 2014

\section{Submit your next manuscript to BioMed Central and we will help you at every step:}

- We accept pre-submission inquiries

- Our selector tool helps you to find the most relevant journal

- We provide round the clock customer support

- Convenient online submission

- Thorough peer review

- Inclusion in PubMed and all major indexing services

- Maximum visibility for your research

Submit your manuscript at www.biomedcentral.com/submit 